\title{
Association between genetic polymorphisms in the cyclooxygenase-1 gene promoter and peptic ulcers in Japan
}

\author{
TOMIYASU ARISAWA, TOMOMITSU TAHARA, TOMOYUKI SHIBATA, MITSUO NAGASAKA, \\ MASAKATSU NAKAMURA, YOSHIO KAMIYA, HIROSHI FUJITA, MASAHIKO NAKAMURA, \\ DAISUKE YOSHIOKA, YUKO ARIMA, MASAAKI OKUBO, ICHIRO HIRATA and HIROSHI NAKANO
} Department of Gatroenterology, Fujita Health University School of Medicine,
1-98 Dengakugakubo, Kutsukake-cho, Toyoake 470-1192, Japan

Received April 30, 2007; Accepted June 4, 2007

\begin{abstract}
Cyclooxygenase-1 (COX-1) has been regarded as a constitutively expressed enzyme that generates prostaglandins for gastrointestinal integrity. We attempted to clarify the association between potentially functional polymorphisms (T-1676C and A-842G/C50T) in the COX-1 gene promoter and gastroduodenal disorders in a Japanese population. The study was performed with 480 stocked DNAs from subjects (gastric ulcers in 93 subjects and duodenal ulcers in 44) with no evidence of gastric malignancy. We employed the PCRSSCP method to detect gene polymorphisms. The severity of histological chronic gastritis in antral biopsy specimens was classified according to the updated Sydney system. The T$1676 \mathrm{C}$ polymorphism was not associated with either gastric mucosal atrophy or infiltration of inflammatory cells into gastric mucosa. In non-NSAID (non-steroidal antiinflammatory drug) users, male gender and Helicobacter pylori (HP) infection were significantly associated with both gastric and duodenal ulcers, whereas the $-1676 \mathrm{~T}$ allele carrier was significantly associated with only gastric ulcers (OR, 2.86; 95\% CI, 1.29-6.34). In NSAID users, the number of -1676T alleles was significantly associated with developing gastroduodenal ulcers (OR, 5.80; 95\% CI, 1.59-21.1), whereas male gender and HP infection were not. The $-842 \mathrm{~T} /$ C50T polymorphism was not detected in any of the 480 Japanese subjects. In conclusion, a carrier of the $-1676 \mathrm{~T}$ allele in the COX-1 gene promoter, as well as HP infection and male gender, seem to be significant risk factors for developing gastric ulcers, and the number of $-1676 \mathrm{~T}$ alleles was also a significant risk factor for the NSAID-induced ulcer, whereas the frequency of the A-842G polymorphism was thought to be very rare in the Japanese population.
\end{abstract}

Correspondence to: Dr Tomiyasu Arisawa, 1-98 Dengakugakubo, Kutsukake-cho, Toyoake 470-1192, Japan

E-mail: tarisawa@fujita-hu.ac.jp

Key words: cyclooxygenase-1, gene polymorphism, gastritis, peptic ulcer, non-steroidal anti-inflammatory drug

\section{Introduction}

It is well known that Helicobacter pylori (HP) infection and non-steroidal anti-inflammatory drug (NSAID) use are major contributing factors to the development of peptic ulcers (1). Recently, although new occurrences of peptic ulcers are decreased by eradication of HP, NSAID-induced ulcers are not decreased. NSAID induces gastric mucosal damage, including bleeding, ulceration, and perforation (2). These effects are caused by the inhibition of cyclooxygenase (COX), which catalyses the formation of prostaglandin (PG) from arachidonic acid (3). PGs are involved in a variety of physiological processes in the stomach, including acid secretion, production of mucus and mucosal blood flow (4). COX exists as two isozymes referred to as COX-1 and COX-2. There is ubiquitous expression of COX-1 in the normal gastric mucosa where it contributes in large part to PG synthesis (5). The use of a COX-1 inhibitor is well known to be associated with a higher risk of complicated ulcer disease compared with a COX-2 inhibitor (6). Therefore, the ulcerogenic effects of NSAID are thought to be the consequence of the inhibition of COX-1.

Appreciable genetic diversity seems to exist within the COX-1 locus and at least nine single-nucleotide polymorphisms (SNPs) have been identified (7). In this study, A-842G and C50T, which are in complete linkage disequilibrium, have been demonstrated as functional polymorphisms. That is, heterozygotes for A-842G/C50T exhibited high sensitivity to aspirin and had lower PG synthesis capacity compared with the wild-type. This fact suggests that the $-842 \mathrm{G}$ carrier has a higher risk of developing NSAID-induced ulcer. Although Oijen et al reported that the COX-1 A-842G/C50T polymorphism did not influence the risk for developing peptic ulcer bleeding (8), the role of this polymorphism on the development of peptic ulcers still remains unclear. In addition, Shi et al have investigated the association of 4 of 20 known informative and potentially functional polymorphisms in the COX-1 gene with asthma (9). However, there has been no report regarding an association between these polymorphisms and gastroduodenal disorder.

In this study, we attempted to clarify the association between gastroduodenal disorders and genetic polymorphisms, including A-842G/C50T and rs 1330344 (T- 
$1676 \mathrm{C})$ in the 5 '-upstream region of the COX-1 gene in Japan.

\section{Materials and methods}

Clinical samples. We randomly selected 386 samples from our stocked DNA from patients enrolled at the Endoscopy Center of Fujita Health University Hospital in 2006. All the patients underwent upper gastrointestinal endoscopy and, from some, biopsy specimens were taken from antral mucosa. Part of each specimen was fixed in $10 \%$ buffered formalin and embedded in paraffin, while the other part was immediately frozen and stored at $-80^{\circ} \mathrm{C}$. Finally, the study population comprised 480 subjects with no neoplastic lesions, including 94 healthy volunteers also randomly selected from our stocked DNA.

All histological diagnoses were made at the Department of Pathology of our hospital. The severity of chronic gastritis was also classified according to the updated Sydney system (10) by a pathologist who had no access to clinical information. According to the severity of gastric mucosal atrophy, the subjects were divided into the following 3 groups: the non-atrophy (NA) group (atrophy score $=0$ and metaplasia score $=0$ ), the severe atrophy (SA) group (atrophy score $\geq 2$ or metaplasia score $\geq 2$ ), and the mild atrophy (MA) group (all others). The HP infection status was assessed by serology, histological examination, or the urea breath test. Patients were diagnosed as having infection when at least one of the diagnostic tests was positive.

The Ethics Committee of Fujita Health University School of Medicine approved the protocol, and written informed consent was obtained from all of the participating subjects.

Genotyping of polymorphisms. Sample stocked DNAs isolated from biopsy specimens or peripheral blood were used. Polymorphism was genotyped by the PCR-SSCP method as reported previously $(11,12)$. To detect the A-842G/ C50T polymorphism, two primer sets were prepared. First, using the primer pair $(842 \mathrm{~F}, 5$ '-TGCTATTAAGCCGATT TTATAGATGAG-3' and 842R, 5'-TAGTTCAAATCCG ACTCCACAGC), PCR was carried out in a volume of $20 \mu \mathrm{l}$ containing $0.1 \mu \mathrm{g}$ of genomic DNA. The DNA was denatured at $96^{\circ} \mathrm{C}$ for $90 \mathrm{sec}$, followed by 35 cycles at $96^{\circ} \mathrm{C}$ for $15 \mathrm{sec}, 58^{\circ} \mathrm{C}$ for $30 \mathrm{sec}$, and $72^{\circ} \mathrm{C}$ for $45 \mathrm{sec}$, with final extension at $72^{\circ} \mathrm{C}$ for $5 \mathrm{~min}$. In addition, using the other primer set $\left(842 \mathrm{~F} 2,5^{\prime}\right.$-CGATAACTGAGCACCTACTAC ATGCTGG-3' and 842R2, 5'-GAGAGCCTAGTTCAAA TCCAGACTCCAC-3'), the PCR reaction was conducted with a $60^{\circ} \mathrm{C}$ annealing temperature in a similar manner. Thereafter, $2 \mu \mathrm{l}$ of the PCR product was denatured with $10 \mu \mathrm{l}$ of formamide (Sigma-Aldrich Co., St. Louis, USA) at $90^{\circ} \mathrm{C}$ for $5 \mathrm{~min}$. SSCP was carried out at $12^{\circ} \mathrm{C}$ using a GenePhor DNA separation system with GeneGel Excel 12.5/24 (Amersham Biosciences Corp., USA), after which the denatured single-strand DNA bands were detected using a DNA Silver Staining kit (Amersham Biosciences Corp.).

To detect the T-1676C polymorphism, using the primer set (1676F, 5'-GATTCTGAGGTGAAGGCTCTTCCCAT-3' and 1676R, 5'-TTTCTGGTGAGAAGAAAGGAGAGACGG-3'), the $\mathrm{PCR}$ reaction was carried out with a $56^{\circ} \mathrm{C}$ annealing a)

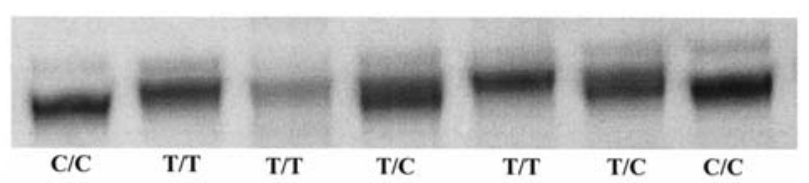

b)

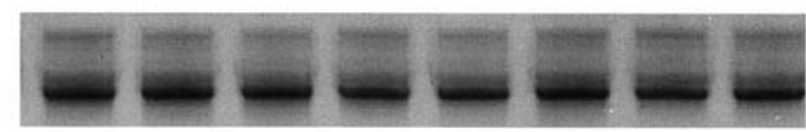

c)

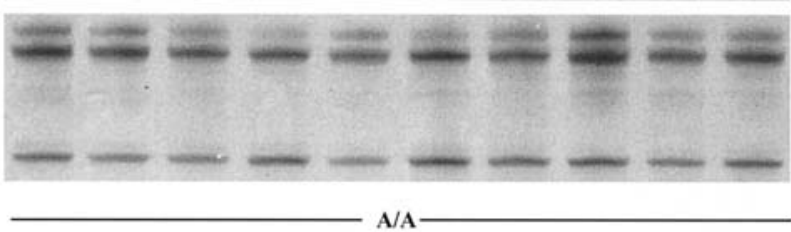

Figure 1. PCR-SSCP images. (a) T-1676C polymorphism, (b) A-842G polymorphism (using $842 \mathrm{~F}$ and $842 \mathrm{R}$ primer set), and (c) A-842G polymorphism (using $842 \mathrm{~F} 2$ and $842 \mathrm{R} 2$ primer set). The A-842G polymorphism was not detected in any of the subjects.

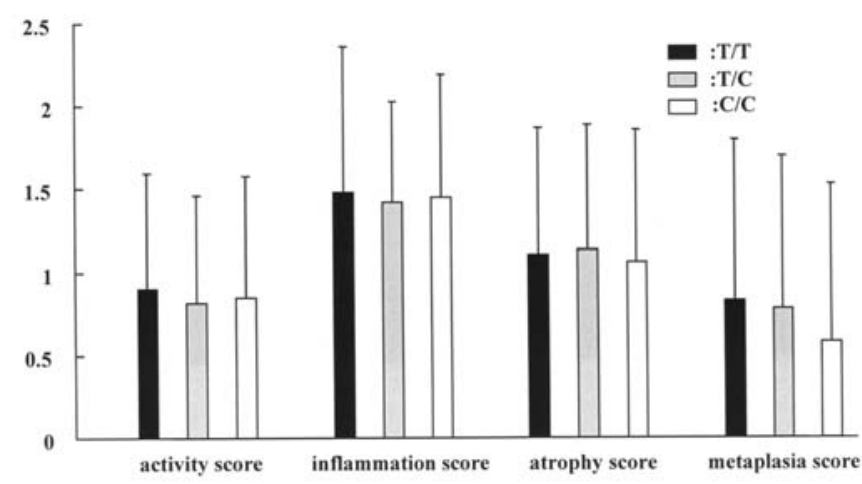

Figure 2. The relationship between the T-1676C genotype and the updated Sydney system scores. There were no significant differences among the 3 genotypes.

temperature as described above. SSCP was also carried out at $12^{\circ} \mathrm{C}$ as described above.

Statistical analysis. The odds ratio (OR) and 95\% confidence intervals (CI) were estimated by logistic regression analysis after adjustment for age, gender and $H$. pylori infection status. The Mann-Whitney U test was employed to assess the association between the COX-1 polymorphism and the updated Sydney system scores. For all analyses, the level of significance was set at $\mathrm{p}<0.05$.

\section{Results}

Detection of the A-842G and T-1676C polymorphisms. As shown in Fig. 1, single-strand DNAs of both A-842G/C50T and T-1676C were clearly separated by SSCP. A singlestrand band of the $-842 \mathrm{G}$ allele was not detected in any of the 480 Japanese subjects. Therefore, the associations of the A-842G/C50T polymorphism with gastroduodenal disorders could not be analyzed. 
Table I. Association of T-1676C with gastric mucosal atrophy.

\begin{tabular}{|c|c|c|c|c|}
\hline & Volunteer & NA group & MA group & SA group \\
\hline Number of subjects & 94 & 82 & 100 & 105 \\
\hline Male:female & $58: 36$ & $42: 40$ & $56: 44$ & $78: 27$ \\
\hline Mean age \pm SD & $27.15 \pm 7.34$ & $58.31 \pm 14.33$ & $60.37 \pm 14.16$ & $63.51 \pm 10.51$ \\
\hline HP positivity & - & $14.6 \%$ & $74.7 \%$ & $99.0 \%$ \\
\hline \multicolumn{5}{|l|}{ T-1676C (rs1340344) } \\
\hline $\mathrm{T} / \mathrm{T}$ & 23 & 23 & 30 & 28 \\
\hline $\mathrm{T} / \mathrm{C}$ & 54 & 38 & 44 & 53 \\
\hline $\mathrm{C} / \mathrm{C}$ & 17 & 21 & 26 & 24 \\
\hline $\mathrm{C}$ allele frequency & $46.8 \%$ & $48.8 \%$ & $48.0 \%$ & $48.1 \%$ \\
\hline \multicolumn{5}{|l|}{$\mathrm{T}$ carrier vs $\mathrm{C} / \mathrm{C}$} \\
\hline OR (95\% CI) & $2.25(0.57-8.84)$ & Reference & $0.98(0.42-2.30)$ & $1.53(0.40-5.93)$ \\
\hline $\mathrm{p}$ value & $\mathrm{p}=0.25$ & & $\mathrm{p}=0.97$ & $\mathrm{p}=0.54$ \\
\hline \multicolumn{5}{|l|}{$\mathrm{T} / \mathrm{T}$ vs others } \\
\hline OR $(95 \% \mathrm{CI})$ & $0.95(0.26-3.50)$ & Reference & $1.00(0.44-2.28)$ & $1.09(0.27-4.51)$ \\
\hline p-value & $\mathrm{p}=0.94$ & & $\mathrm{p}=0.99$ & $\mathrm{p}=0.90$ \\
\hline
\end{tabular}

Volunteer, healthy subject with no symptoms; NA, non-atrophy; MA, mild atrophy; SA, severe atrophy. Analysis was performed by logistic regression analysis after adjustment for age, gender and HP status. The frequency of T-1676C was not significantly different among the 4 groups.

Table II. Association of T-1676C with peptic ulcers.

\begin{tabular}{|c|c|c|c|c|}
\hline & Non-ulcer & Peptic ulcer & Gastric ulcer & Duodenal ulcer \\
\hline Number of subjects & 343 & 137 & 93 & 44 \\
\hline Male:female & 179:164 & $102: 35$ & $70: 23$ & $32: 12$ \\
\hline Mean age \pm SD & $52.44 \pm 19.71$ & $62.91 \pm 13.64$ & $65.75 \pm 11.37$ & $56.89 \pm 16.03$ \\
\hline HP positivity & $55.2 \%$ & $82.2 \%$ & $85.7 \%$ & $75.0 \%$ \\
\hline \multicolumn{5}{|l|}{ T-1676C (rs1340344) } \\
\hline $\mathrm{T} / \mathrm{T}$ & 90 & 43 & 28 & 15 \\
\hline $\mathrm{T} / \mathrm{C}$ & 169 & 71 & 54 & 17 \\
\hline $\mathrm{C} / \mathrm{C}$ & 84 & 23 & 11 & 12 \\
\hline $\mathrm{C}$ allele frequency & $49.1 \%$ & $42.7 \%$ & $40.9 \%$ & $46.6 \%$ \\
\hline \multicolumn{5}{|l|}{$\mathrm{T}$ carrier vs $\mathrm{C} / \mathrm{C}$} \\
\hline OR (95\% CI) & Reference & $1.88(1.07-3.30)$ & $2.71(1.31-5.62)$ & $1.06(0.50-2.25)$ \\
\hline $\mathrm{p}$ value & & $p=0.027$ & $\mathrm{p}=\mathbf{0 . 0 0 7 3}$ & $\mathrm{p}=0.88$ \\
\hline \multicolumn{5}{|l|}{ T/T vs others } \\
\hline OR (95\% CI) & Reference & $1.33(0.81-2.19)$ & $1.22(0.68-2.18)$ & $1.47(0.72-3.00)$ \\
\hline p-value & & $\mathrm{p}=0.26$ & $\mathrm{p}=0.51$ & $\mathrm{p}=0.29$ \\
\hline
\end{tabular}

Analysis was performed by logistic regression analysis after adjustment for age, gender and HP status.

The association of T-1676C with chronic gastritis. Histological findings of chronic gastritis were assessed in 287 of 386 subjects. With respect to gastric mucosal atrophy, 82, 100 , and 105 of the subjects were classified into the NA, MA, and SA groups, respectively (Table I). The male:female ratio was higher in the SA group than in the other groups. Regarding the HP-positive rate, there were significant differences among the 3 groups ( $\mathrm{SA}>\mathrm{MA}>\mathrm{NA})$. The frequency of the $-1676 \mathrm{C}$ allele was not significantly different among the 4 groups, including the group of 94 volunteers, by logistic regression analysis after adjustment for age, gender, and HP status. In addition, the associations between T-1676C and each updated Sydney system score are shown in Fig. 2. There were no significant differences among the 3 genotypes. 
Table III. Association of T-1676C with gastroduodenal ulcers in the NSAID users.

\begin{tabular}{|c|c|c|c|c|}
\hline & Non-ulcer & NSAID ulcer & Gastric ulcer & Duodenal ulcer \\
\hline Number of subjects & 22 & 25 & 19 & 6 \\
\hline Male:female & $10: 12$ & $16: 9$ & $12: 7$ & $4: 2$ \\
\hline Mean age \pm SD & $69.32 \pm 9.59$ & $68.16 \pm 11.69$ & $71.26 \pm 9.98$ & $58.33 \pm 12.01$ \\
\hline HP positivity & $50.0 \%$ & $56.5 \%$ & $64.7 \%$ & $33.3 \%$ \\
\hline \multicolumn{5}{|l|}{ T-1676C (rs1340344) } \\
\hline $\mathrm{T} / \mathrm{T}$ & 2 & 14 & 9 & 5 \\
\hline $\mathrm{T} / \mathrm{C}$ & 17 & 9 & 8 & 1 \\
\hline $\mathrm{C} / \mathrm{C}$ & 3 & 2 & 2 & 0 \\
\hline $\mathrm{C}$ allele frequency & $52.3 \%$ & $26.0 \%$ & $31.6 \%$ & $8.3 \%$ \\
\hline \multicolumn{5}{|l|}{$\mathrm{T} / \mathrm{T}$ vs others } \\
\hline OR $(95 \% \mathrm{CI})$ & Reference & $16.7(2.56-108.7)$ & $8.30(1.23-56.1)$ & - \\
\hline $\mathrm{p}$ value & & $p=0.0032$ & $\mathrm{p}=\mathbf{0 . 0 3 0}$ & - \\
\hline \multicolumn{5}{|l|}{$\mathrm{T}$ carrier vs $\mathrm{C} / \mathrm{C}$} \\
\hline OR $(95 \% \mathrm{CI})$ & Reference & $2.22(0.54-9.17)$ & $1.68(0.37-7.55)$ & - \\
\hline p-value & & $\mathrm{p}=0.27$ & $\mathrm{p}=0.50$ & - \\
\hline
\end{tabular}

Analysis was performed by logistic regression analysis after adjustment for age, gender and HP status. (-) could not be calculated.

Table IV. Association between non-NSAID- or NSAID-induced ulcers and various risk factors.

\begin{tabular}{|c|c|c|}
\hline & \multicolumn{2}{|c|}{ OR ( $95 \%$ confidence intervals) } \\
\hline & Unadjusted odds ratio & Adjusted odds ratio ${ }^{a}$ \\
\hline \multicolumn{3}{|l|}{ Non-NSAID gastric ulcer } \\
\hline -1676T carrier & $2.44(1.16-5.12)$ & $2.86(1.29-6.34)$ \\
\hline Male gender & $3.05(1.68-5.53)$ & $2.76(1.44-5.29)$ \\
\hline HP infected & $7.60(3.33-17.3)$ & $7.01(3.02-16.2)$ \\
\hline \multicolumn{3}{|l|}{ Non-NSAID duodenal ulcer } \\
\hline -1676T carrier & $0.73(0.35-1.52)$ & $0.90(0.41-1.97)$ \\
\hline Male gender & $2.35(1.11-5.01)$ & $2.38(1.08-5.23)$ \\
\hline HP infected & $3.51(1.48-8.33)$ & $3.29(1.36-7.94)$ \\
\hline \multicolumn{3}{|l|}{ NSAID-induced ulcer } \\
\hline The number of $-1676 \mathrm{~T}$ alleles & $4.82(1.50-15.5)$ & $5.80(1.59-21.1)$ \\
\hline Male gender & $2.13(0.66-6.88)$ & $4.28(0.97-18.8)$ \\
\hline HP infected & $1.30(0.40-4.21)$ & $1.73(0.41-7.39)$ \\
\hline
\end{tabular}

aAdjusted for gender, age, and HP infection status.

The association of T-1676C with gastroduodenal ulcers. Out of 480 subjects, there were 137 subjects with peptic ulcers (93 with gastric ulcers and 44 with duodenal ulcers, Table II). Compared with the non-ulcer group including 94 volunteers, mean age, male:female ratio and HP positivity were higher in the ulcer group. The frequency of the $-1676 \mathrm{C}$ allele was decreased in the subjects with peptic ulcers, especially with gastric ulcers. The frequency of the $-1676 \mathrm{~T}$ allele carrier was significantly higher in the ulcer group (OR, 1.88; 95\% CI, $1.07-3.30 ; \mathrm{p}=0.027)$, especially in the gastric ulcer group (OR, 2.71; 95\% CI, 1.31-5.62; $\mathrm{p}=0.0073)$, than that in the non-ulcer group. On the other hand, there were no significant differences between the non-ulcer group and the duodenal ulcer group.

The association of T-1676C with non-NSAID- or NSAIDinduced ulcers. Among the 480 subjects, there were 47 NSAID users, of whom 19 subjects had gastric ulcers and 6 subjects had duodenal ulcers (Table III). Compared with 22 NSAID users without ulcers, the male:female ratio was higher in the NSAID-induced ulcer group, whereas HP positivity was lower in the NSAID-induced duodenal ulcer group. The 
frequency of the $-1676 \mathrm{C}$ allele was prominently decreased in the NSAID-induced ulcer group, especially in the duodenal ulcer group. In all NSAID users, the frequency of the -1676 $\mathrm{T} / \mathrm{T}$ genotype was significantly higher in the ulcer group than that in the non-ulcer group (OR, 16.7; 95\% CI, 2.56-108.7; $\mathrm{p}=0.0032)$. In the NSAID-induced gastric ulcer group, the frequency of the $\mathrm{T} / \mathrm{T}$ genotype was also significantly higher than that in the non-ulcer group (OR, 8.30; 95\% CI, 1.23$56.1 ; \mathrm{p}=0.030)$.

In non-NSAID users, male gender (OR, 2.76; 95\% CI, 1.44-5.29 and OR, 2.38; 95\% CI, 1.08-5.23, respectively) and HP infection (OR, 7.01; 95\% CI, 3.02-16.2 and OR, 3.29; 95\% CI, 1.36-7.94, respectively) were statistically significantly associated with both gastric and duodenal ulcers, whereas the -1676T carrier (OR, 2.86; 95\% CI, 1.29-6.34) was significantly associated with gastric ulcers, not with duodenal ulcers (Table IV). However, in the NSAID users, only the number of -1676T alleles (OR, 5.80; 95\% CI, 1.59-21.1) was significantly associated with developing ulcers, whereas male gender and HP infection were not.

\section{Discussion}

In this study, we examined the association between gastroduodenal disorders and polymorphisms in the 5'-upstream region of the COX-1 gene. The A-842G/C50T and T-1676C polymorphisms seemed to be informative and potentially functional promoter polymorphisms (9). There is no published information on the frequencies of these polymorphisms in the Japanese population. Our data indicated that the A-842G/ C50T polymorphism was not detected in the Japanese population, although a frequency of $18 \%$ for this polymorphism was reported in a healthy Caucasian population by Halushka et al (7). On the other hand, a significant association between the T-1676C polymorphism (rs 1330344), for which the genotype was in Hardy-Weinberg equilibrium, and the development of ulcer disease, as well as NSAID-induced ulcers, was observed in our Japanese population.

Shi et al selected 4 from 20 SNPs located in the promoter and coding region of the COX-1 gene by searching the National Center for Biotechnology Information (NCBI) website (www.ncbi.nlm.nih.gov/SNP) and SNPper databases (13) in their previous report (9). We excluded 2 of these 4 polymorphisms because $\mathrm{C}-8592 \mathrm{~T}$ was located at a distant position from starting codon $\mathrm{ATG}$, and $\mathrm{C} 22 \mathrm{~T}$ was reported to have the variant allele frequency of $2.3 \%$ in the Japanese population according to the NCBI website. Thus, the remaining polymorphisms, T-1676C and A-842G/C50T in the promoter, were investigated in this study. The results from the study by Halushka et al showed that heterozygosity of the A-842G polymorphism appeared to be in complete linkage disequilibrium with the $\mathrm{C} 50 \mathrm{~T}$, and the resulting amino acid substitution (P17L) was associated with decreased PGH2 synthesis after acetylsalicylic acid administration (7). On the other hand, although the T-1676C promoter polymorphism did not affect the two Sp1 binding sites that were reported to be essential for COX-1 transcription (14), putative transcription factor (GATA-1, CdxA) binding sites were altered by this polymorphism (15). The relationship between the A-842G/C50T polymorphism and human disorders was investigated in several reports $(8,16-18)$, whereas only a few studies have researched the association of the T-1676C polymorphism with human diseases. Shi et al reported that the COX-1 polymorphisms including the T-1676C polymorphism do not appear to play a substantial role in genetic predisposition for asthma or asthma severity (9). However, in their report, the frequency of the $-1676 \mathrm{~T}$ allele was increased and that of the 50T allele was decreased in patients with severe asthma compared with control subjects (78.4 vs. $83.1 \%$ and 7.8 vs. $6.1 \%$, respectively). In addition, this study also demonstrated the association between the T/T/C/C haplotype (-8592/-1676/22/50) and aspirin-intolerant asthma $(\mathrm{p}=0.09)$. Thus, the $-1676 \mathrm{~T}$ allele might affect the bronchoprotective roles of prostaglandins.

The results of our study demonstrated no association of the $\mathrm{T}-1676 \mathrm{C}$ polymorphism with either gastric mucosal atrophy or infiltration of inflammatory cells into gastric mucosa. However, the frequency of the $-1676 \mathrm{~T}$ carrier was significantly higher in patients with ulcer disease, especially gastric ulcer, than that in non-ulcer subjects. Although the mechanisms of developing peptic ulcers still remain unclear, peptic ulcers are not always developed with severe chronic gastritis. Furthermore, although prostaglandins have protective effects on both gastric and duodenal mucosal injuries, there appear to be different mechanisms between gastric and duodenal ulcers. In fact, NSAID-induced mucosal injuries are more often detected in the stomach than in the duodenum (19). Therefore, the T-1676C polymorphism in the COX-1 gene promoter seems to be associated with ulceration in the stomach via the breaking of gastric mucosal integrity, not with gastric inflammation.

Our results showed that, in non-NSAID users, HP infection and male gender were significant risk factors for both gastric and duodenal ulcers, whereas the $-1676 \mathrm{~T}$ carrier was a significant risk factor for gastric ulcers not for duodenal ulcers. In addition, the number of $-1676 \mathrm{~T}$ alleles was a significant risk factor for developing ulcer diseases in NSAID users, whereas HP infection and male gender were not. The frequency of the $-1676 \mathrm{C}$ allele in our studied NSAID users was lower than that in the volunteer group (38.3 vs. $46.8 \%$, respectively). However, the frequency of the $-1676 \mathrm{C}$ allele in subjects with no ulcers $(52.3 \%)$ was inversely higher than that in the volunteers. These findings indicated that NSAID users with no symptoms did not undergo endoscopic examinations. Bernersen et al reported that only $1 \%$ of asymptomatic subjects had peptic ulcer disease (20). Although 25 of the 47 studied NSAID users had gastric or duodenal ulcers (53.2\%), Laine and colleagues showed in a recent study that the incidence of peptic ulcer disease was 4.9 and $14.3 \%$ in aspirin and NSAID users, respectively (21). It is possible that our studied subjects included relatively few NSAID users with no ulcers (potential $-1676 \mathrm{C}$ allele carriers). If all the NSAID users with or without symptoms had undergone endoscopic examination, the significance of the T-1676C polymorphism on NSAID-induced ulcers may have been clearer.

The results from our data suggest that HP infection does not influence the development of NSAID-induced ulcers. However, the interaction between HP infection and NSAID use on developing peptic ulcers still remains controversial 
(22-25). However, it is believed improbable that an eradication therapy for HP completely avoids the risk for NSAID-induced ulcers. To prevent against NSAID-induced peptic ulcers, treatment with proton pump inhibitors or prostaglandin preparations for all NSAID users has been recommended on the basis of accumulated evidence (26-28). Detecting the high-risk group for developing NSAIDinduced ulcer diseases by an assessment for the genotype of the $\mathrm{T}-1676 \mathrm{C}$ polymorphism may save medical costs to a large extent.

In conclusion, the $-1676 \mathrm{~T}$ carrier of the COX-1 gene promoter, as well as infection with HP and male gender, were significantly associated with developing gastric ulcers and the number of $-1676 \mathrm{~T}$ alleles was also significantly associated in NSAID users, whereas the frequency of the A-842G/C50T polymorphism was thought to be very rare in the Japanese population.

\section{References}

1. Wolfe MM, Lichtenstein DR and Singh G: Gastrointestinal toxicity of nonsteroidal antiinflammatory drugs. N Engl J Med 340: 1888-1899, 1999.

2. Garcia Rodriguez LA and Jick H: Risk of upper gastrointestinal bleeding and perforation associated with individual nonsteroidal anti-inflammatory drugs. Lancet 343: 769-772, 1994.

3. McCarthy DM: Mechanisms of mucosal injury and healing: the role of non-steroidal anti-inflammatory drugs. Scand J Gastroenterol (Suppl) 208: 24-29, 1995.

4. Robert A and Ruwart M: Effect of prostaglandins on the digestive system. In: Prostaglandins. Lee JB (ed). Elsevier, New York, pp113-176, 1982.

5. O'Neal GP and Ford-Hutchinson AW: Expression of mRNA for cyclooxygenase-1 and cyclooxygenase- 2 in human tissues. FEBS Lett 330: 156-160, 1993.

6. Bombardier C, Laine L, Reicin A, et al: Comparison of upper gastrointestinal toxicity of rofecoxib and naproxen in patients with rheumatoid arthritis. VIGOR Study Group. N Engl J Med 343: 1520-1528, 2000 .

7. Halushka MK, Walker LP and Halushka PV: Genetic variation in cyclooxygenase 1 : effects on response to aspirin. Clin Pharmacol Ther 73: 122-130, 2003.

8. van Oijen MG, Laheij RJ, Koetsier M, et al: Effect of a specific cyclooxygenase-gene polymorphism (A-842G/C50T) on the occurrence of peptic ulcer hemorrhage. Dig Dis Sci 51: 2348-2352, 2006.

9. Shi J, Misso NL, Duffy DL, et al: Cyclooxygenase-1 gene polymorphisms in patients with different asthma phenotypes and atrophy. Eur Respir J 26: 249-256, 2005.

10. Dixon MF, Genta RM, Yardley JH and Correa P: Classification and grading of gastritis: the updated Sydney system. Am J Surg Pathol 20: 1161-1181, 1996.

11. Arisawa T, Tahara T, Shibata T, et al: The relationship between Helicobacter pylori infection and promoter polymorphism of the Nrf2 gene in chronic gastritis. Int J Mol Med 19: 143-148, 2007.
12. Arisawa T, Tahara T, Shibata T, et al: A polymorphism of microRNA 27a genome region is associated with the development of gastric mucosal atrophy in Japanese male subjects. Dig Dis Sci 52: 1691-1697, 2007.

13. Riva A and Kohane IS: SNPper: retrieval and analysis of human SNPs. Bioinformatics 18: 1681-1685, 2002.

14. Xu XM, Tang JL, Chen X, Wang LH and Wu KK: Involvement of two Sp1 elements in basal endothelial prostaglandin $\mathrm{H}$ synthase-1 promoter activity. J Biol Chem 272: 6943-6950, 1997.

15. Heinemeyer T, Wingender E, Reuter I, et al: Databases on transcriptional regulation: TRANSFAC, TRRD and COMPEL. Nucleic Acids Res 26: 362-367, 1998.

16. Gonzalez-Conejero R, Rivera J, Corral J, Acuna C, Guerrero JA and Vicente V: Biological assessment of aspirin efficacy on healthy individuals: heterogeneous response or aspirin failure? Stroke 36: 276-280, 2005

17. Maree AO, Curtin RJ, Chubb A, et al: Cyclooxygenase-1 haplotype modulates platelet response to aspirin. J Thromb Haemost 3: 2340-2345, 2005.

18. Lepantalo A, Mikkelsson J, Resendiz JC, et al: Polymorphisms of COX-1 and GPVI associate with the antiplatelet effect of aspirin in coronary artery disease patients. Thromb Haemost 95: 253-259, 2006.

19. Dajani EZ and Agrawal NM: Prevention of nonsteroidal antiinflammatory drug-induced gastroduodenal ulcers: role of mucosal protective and gastric antisecretory drugs. Dig Dis 13 (suppl 1): 48-61, 1995.

20. Bernersen B, Johnsen R, Straume B, Burhol PG, Jenssen TG and Stakkevold PA: Towards a true prevalence of peptic ulcer: the Sorreisa gastrointestinal disorder study. Gut 31: 989-992, 1990.

21. Laine L, Maller ES, Yu C, Quan H and Simon T: Ulcer formation with low-dose enteric-coated aspirin and the effect of COX-2 selective inhibition: a double-blind trial. Gastroenterology 127: 395-402, 2004.

22. Matsukawa Y, Aoki M, Nishinarita S, et al: Prevalence of Helicobacter pylori in NSAID users with gastric ulcer. Rheumatology 42: 947-950, 2003.

23. Chan FK: NSAID-induced peptic ulcers and Helicobacter pylori infection: implications for patient management. Drug Saf 28: 287-300, 2005.

24. Zapata-Colindres JC, Zepeda-Gomez S, Montano-Loza A, Vazquez-Ballesteros E, de Jesus Villalobos J and Valdovinos-Andraca F: The association of Helicobacter pylori infection and nonsteroidal anti-inflammatory drugs in peptic ulcer disease. Can J Gastroenterol 20: 277-280, 2006.

25. Ji KY and Hu FL: Interaction or relationship between Helicobacter pylori and non-steroidal anti-inflammatory drugs in upper gastrointestinal diseases. World J Gastroenterol 12: 3789-3792, 2006.

26. Graham DY, Agrawal NM, Campbell DR, et al: Ulcer prevention in long-term users of nonsteroidal anti-inflammatory drugs: results of a double-blind, randomized, multicenter, active- and placebo-controlled study of misoprostol vs lansoprazole. Arch Int Med 162: 169-175, 2002.

27. Garcia Rodrigues LA and Hernandez-Diaz S: Relative risk of upper gastrointestinal complications among users of acetaminophen and nonsteroidal anti-inflammatory drugs. Epidemiology 13: 570-576, 2001.

28. Rostom A, Wells G, Tugwell P, Welch V, Dube C and McGowan J: The prevention of chronic NSAID-induced upper gastrointestinal toxicity: a Cochrane collaboration metaanalysis of randomized controlled trials. J Rheumatol 27: 2203-2214, 2000 . 